\title{
Design and FE Modeling of UPVC Corrugated Hollow Roofing Sheet
}

\author{
Djoko Setyanto
}

Mechanical Engineering Department, Faculty of Engineering, Atma Jaya Catholic University of Indonesia, Jalan Jenderal Sudirman 51 Jakarta 12930, Indonesia

\begin{abstract}
The corrugated roofing sheet of UPVC polymer material is the potential material to replace common roof materials that has been developed in Indonesia. This study describes the design of the roof profile and analysis of the roof structure to static load. The resulting roof profile is a hollow corrugated roofing sheet with five crests and four valleys. The effective width is $860 \mathrm{~mm}, 10 \mathrm{~mm}$ cavity thick, and 45 $\mathrm{mm}$ peak height. The finite element model of the hollow UPVC corrugated sheets roof structure shows that the roof structure is capable of withstanding the static load/ mass of $133 \mathrm{~kg}$ equivalent of two applicators and capable of withstanding the wind lift force equivalent to $99 \mathrm{~km} / \mathrm{h}$.
\end{abstract}

\section{Introduction}

Corrugated roofing sheets of polymeric materials are widely used in Indonesia $[1,2]$. The superiority of the polymeric material is resistant to corrosion, so that the roof is suitable for corrosive areas [3]. Polymeric roofing sheet materials especially glass fibre reinforced polymer (GFRP) has been widely used for corrosive factory and warehouse buildings in Indonesia since 2008 [4, 5]. The weaknesses of GFRP material as a roof are less resistant to fire and the price is still relatively expensive. This deficiency can be filled by rigid polyvinylchloride or unplasticized polyvinylchloride (UPVC) [6, 7]. The advantages of UPVC materials are relatively economical and more resistant to fire than GFRP materials. This study describes the design of the roof profile and analysis of the roof structure to static load.

\section{Method}

The method to design a polymeric roofing sheet is begun with the preparation of product design specification. The next step is the determination of the conceptual design to be realized into the embodiment and detail design [8]. The design result is then realized to be a real product of UPVC roofing sheet using extrusion injection moulding machine. The first step of the design production is the design of the production process of UPVC hollow corrugated roofing sheet. Then the second step is trial production. The detailed design of polymer roofing sheet structure is done by using finite element method. The software used in this study is Solidworks 2015 Education Version [9]. Validation of the finite element model is done by comparing them to the actual structure of UPVC roofing sheet. The parameter of validation is the maximum deflection of the roofing sheet structure against the static load. The parameter of maximum deflection is chosen because the reasonability easy to do and effective for validation.

All the steps are summarized as shown in Figure 1. The experimental testing of the roof structure against the static load is shown in Figure 2.

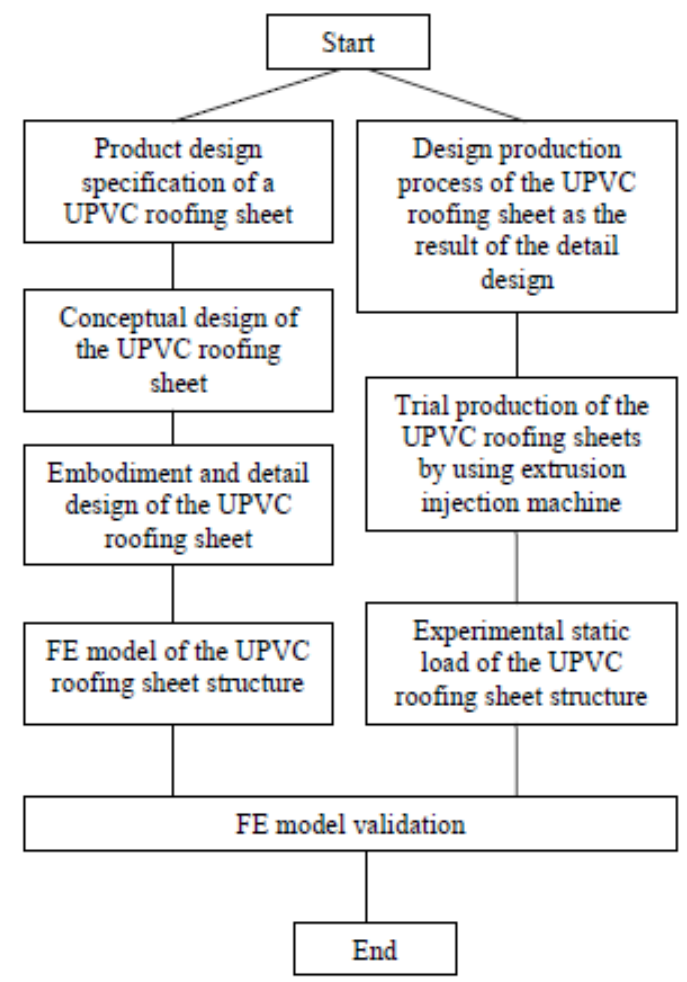

Fig. 1. The steps design and FE modeling of a UPVC Corrugated Hollow Roofing Sheet 


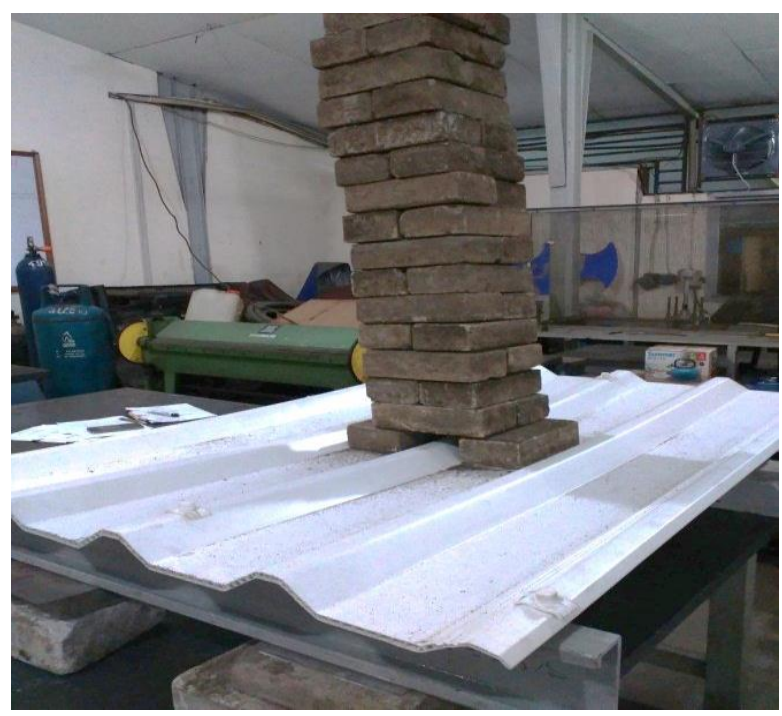

Fig. 2. The experimental static load of the UPVC corrugated hollow roofing sheet structure

\section{Results and discussion}

\subsection{Product design specification and conceptual design of the roofing sheet}

The corrugated roofing sheet is required to meet the following product design specifications,

1) Made of rigid PVC or UPVC polymer.

2) Can accommodate minimum rainfall of $150 \mathrm{~mm} / \mathrm{hr}$ with a slope of up to 5 degrees.

3) Has sufficient strength and stiffness to be used as roof structure with internal spacing of purlins up to $1.2 \mathrm{~m}$.

Table 1. Sub-function of the roofing sheet.

\begin{tabular}{|c|c|c|c|}
\hline \multirow{2}{*}{$\begin{array}{c}\text { Sub- } \\
\text { functions }\end{array}$} & \multicolumn{3}{|c|}{ Alternative of solution } \\
\cline { 2 - 4 } & Solution 1 & Solution 2 & Solution 3 \\
\hline $\begin{array}{c}\text { Polymer } \\
\text { material }\end{array}$ & $\begin{array}{c}\text { Rigid PVC } \\
\text { (UPVC) with } \\
\text { UV inhibitor }\end{array}$ & - & - \\
\hline $\begin{array}{c}\text { Rain fall } \\
\text { capacity } \\
\text { and slope }\end{array}$ & $\begin{array}{c}\text { Spandel } \\
\text { profile }\end{array}$ & $\begin{array}{c}\text { Trimdek } \\
\text { profile }\end{array}$ & New \\
\hline \multirow{2}{*}{ Stiffiness } & $\begin{array}{c}\text { Hollow } \\
\text { sections }\end{array}$ & $\begin{array}{c}\text { Polymer } \\
\text { composite } \\
\text { with fiber } \\
\text { reinforcement }\end{array}$ & \\
\hline
\end{tabular}

The conceptual design will be derived based on the overall function of the roof sheet composed of each subfunction of the constituent. The desired overall function is a rigid PVC or UPVC corrugated roofing sheet that can accommodate $150 \mathrm{~mm} / \mathrm{hr}$ of rainfall at a slope of up to 5 degrees and can be fitted with internal spacing of purlins up to $1.2 \mathrm{~m}$. There are three sub-functions, namely polymer material for roof construction, corrugated profile, and stiffness. Each sub-function will provide one or more solutions. Furthermore, the combination of the three sub-functions will form a whole function or complete solution called conceptual design. There will be plenty of conceptual designs. The selected conceptual design is determined based on the assessment of all sub-functional solutions according to technical and economic criteria. Technical criteria are related to the physical-mechanical properties of the material, easy to manufacture, and the durability of roof for outdoor application. Economic criteria are related to procurement costs and operational/ maintenance costs. Table 1 shows the sub-functions of the roofing sheet.

There are many variants of solution that are a combination of sub-function rows and solution columns. The solution variants are:

1) $1.1-2.1-3.1$

2) $1.1-2.2-3.1$

3) $1.1-2.3-3.1$

4) $1.1-2.1-3.2$, etc

The priority solution that is selected is the variant number 3, i.e. 1.1 - 2.3 - 3.1. The conceptual design number 3 is chosen because the material used must be a rigid PVC or unplasticized polyvinylchloride (UPVC) that is filled with a UV inhibitor. The corrugated profile is a new profile that has a rainfall capacity equivalent or almost the same as the trimdek profile. The rigidity of roof sheet is obtained by choosing hollow roof for the high moment of inertia.

\subsection{Embodiment and detail design of the roofing sheet}

The above step results a conceptual design of a corrugated hollow roofing sheet of UPVC material that has a rainfall capacity equivalent or almost the same as trimdek profile. Same as trimdek profile, this new profile has five peaks and four valleys as shown in Figure 3. The reference profiles, trimdek and spandek are shown in Figure 4 and Figure 5. The width of the plane marked with black dots in Fig. 3-5 shows the area of the rainwater capacity per width of the roof section $\left(\mathrm{mm}^{2} /\right.$ $\mathrm{mm})$.

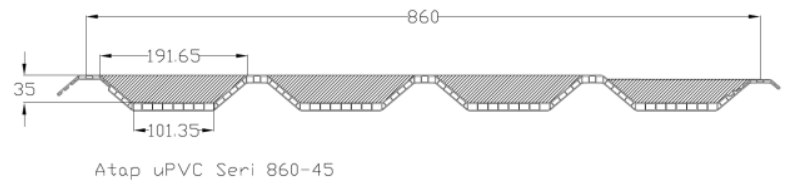

Fig. 3. UPVC corrugated hollow roofing sheet profile

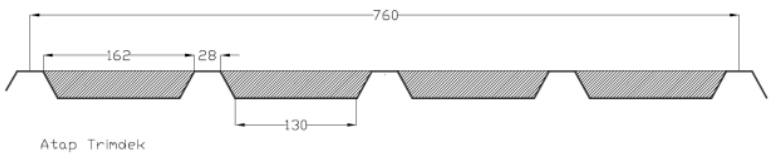

Fig. 4. Trimdek roofing sheet profile [10]

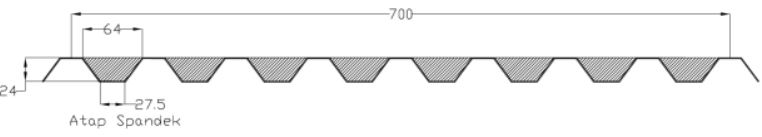

Fig. 5. Spandek roofing sheet profile [10] 
The rainfall capacity of the corrugated roofing sheets of the reference profiles, trimdek and spandek based on Figure 4 and Figure 5 are respectively $24.42 \mathrm{~mm}^{2} / \mathrm{mm}$ and $12.54 \mathrm{~mm}^{2} / \mathrm{mm}$. The maximum roof length for drainage of $150 \mathrm{~mm} / \mathrm{hr}$ of rainfall and 5 degree of slope are respectively $214 \mathrm{~m}$ and $89 \mathrm{~m}$ [10]. The rainfall capacity of the new profile of the UPVC corrugated hollow roofing sheet is $23.84 \mathrm{~mm}^{2} / \mathrm{mm}$ as shown in Figure 3 . The greater the value, the greater the capacity of rainfall. The new profile rainfall capacity is almost the same as the trimdek profile. The top and bottom thickness of the new profile of the hollow UPVC roofing sheet are designed $1 \mathrm{~mm}$ and $0.8 \mathrm{~mm}$. Analysis of the roof structure ability to withstand loads of up to $100 \mathrm{~kg}$ with an internal purlins spacing of $1.2 \mathrm{~m}$ will be shown in the FE model.

\subsection{Trial production of the roofing sheet and testing of the roofing sheet structure}

The cross section of the UPVC corrugated hollow roofing sheet is as shown in Figure 6. The roof thickness is $1 \mathrm{~mm}$ except $0.8 \mathrm{~mm}$ for the top sheet. The injection mould and cooling system for UPVC material are based on the profile.

Rigid PVC or UPVC is thermoplastic type. The thermoplastic is composed of a linear chain which at room temperature is solid and will melt when heated [11]. The process for making corrugated and hollow roofing sheets of UPVC material in general is to use the extrusion and injection processes. The machine's equipments consist of a feeder, screw extruder, heater, nozzle, injection, moulding, cooling, withdraw and cutting. The trial process and result of production of the roofing sheets by extrusion injection moulding machine are shown in Figure 7 and Figure 8.

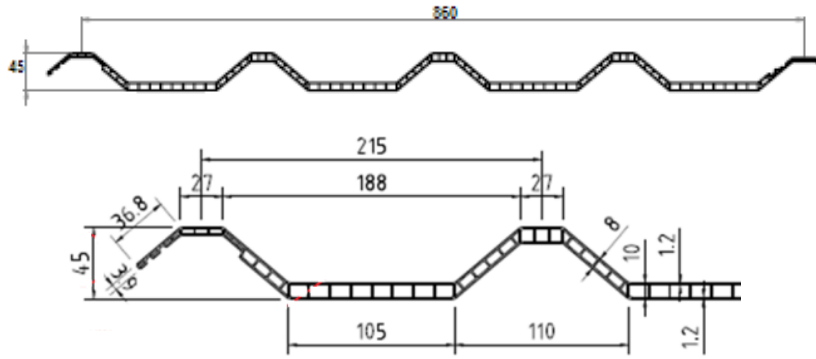

Fig. 6. Cross section of the roofing sheet

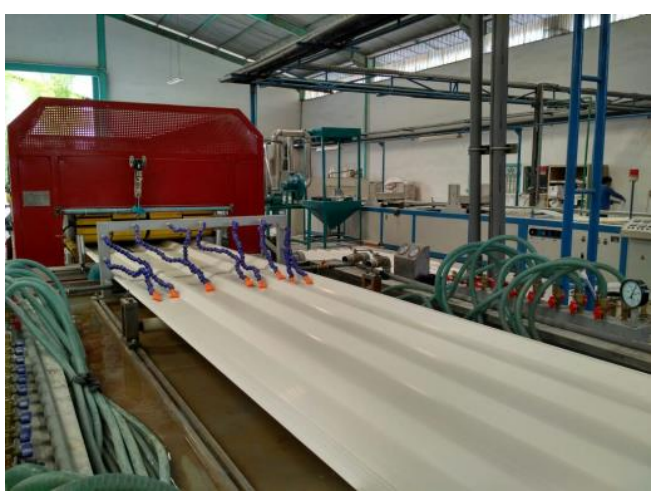

Fig. 7. Process for making the roofing sheet

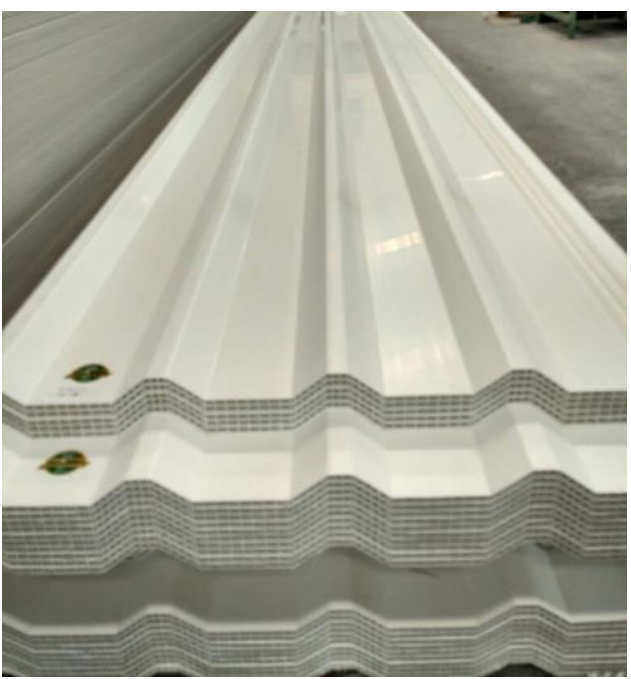

Fig. 8. The UPVC Corrugated Hollow roofing sheet

\subsection{Experimental static load test and FE modeling of the roofing sheet structure}

Figure 9 shows the experimental of the roof structure to static load. The length of the roof sheet is $1.5 \mathrm{~m}$. The roof is supported by two purlins with a distance of $1.2 \mathrm{~m}$. The static load is bricks that are piled on the roof. The roof deflection is measured by dial indicator. The load is placed in two valley areas in the middle of the cross section. Two dial indicators are placed at the bottom of the roof under the loads. Table 2 and Figure 10 show the correlation of load and deflection.

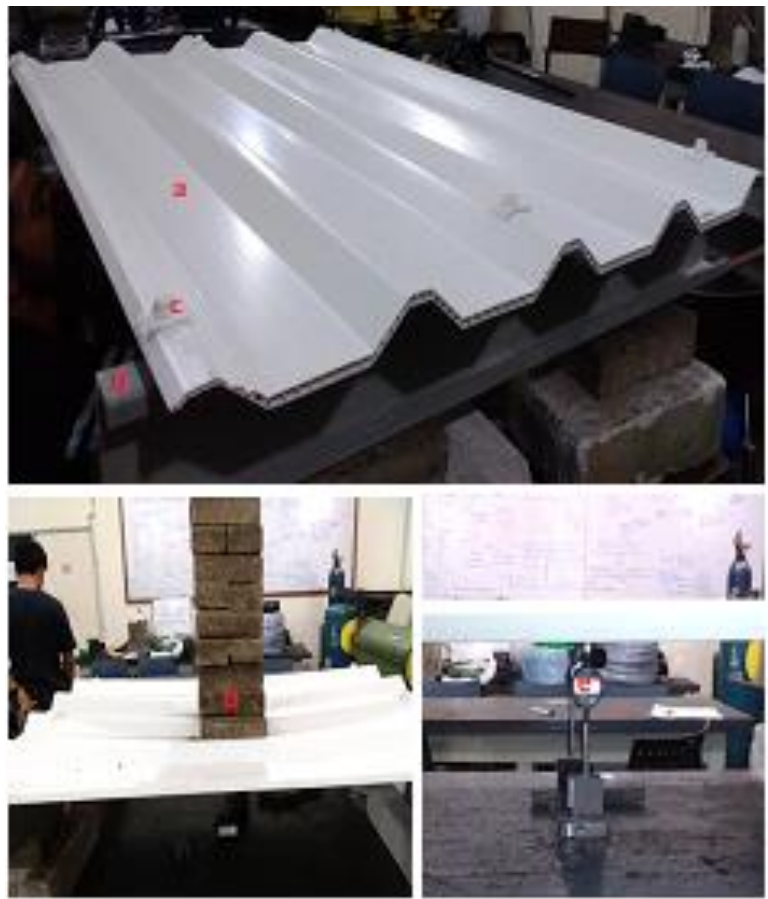

Fig. 9. Experimental roofing sheet structure: (a) roofing sheet, (b) purlins, (c) fasteners, (d) loads, (e) dial indicator

Figure 10 shows that the load and deflection are linearly correlated based on Hooke's law. The two curves that occur are linear curve. It indicates that load up to $100 \mathrm{~kg}$ causes the deflection to remain within the 
elastic region. There is a little difference in deflection between dial 1 and dial 2 . This is due to the unevenness of the bricks load on the roof area above the two dials.

Table 2. Deflection of experimental

\begin{tabular}{|c|c|c|}
\hline \multirow{2}{*}{ Load $(\mathrm{kg})$} & \multicolumn{2}{|c|}{ Deflection (mm) } \\
\cline { 2 - 3 } & Dial 1 & Dial 2 \\
\hline 11.4 & 3.45 & 4.16 \\
\hline 22.3 & 6.87 & 6.9 \\
\hline 33.5 & 10.2 & 9.03 \\
\hline 44.7 & 13.02 & 12.74 \\
\hline 55.7 & 16.76 & 15.04 \\
\hline 67.1 & 20.89 & 17.6 \\
\hline 77.7 & 24.87 & 21.69 \\
\hline 88.7 & 29.4 & 24.74 \\
\hline 100.3 & 33.64 & 28.12 \\
\hline
\end{tabular}

Load vs deflection (Experimental)

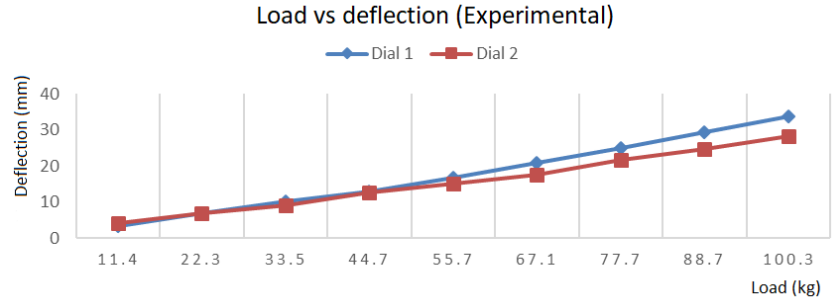

Fig. 10. Load vs deflection of experimental

The finite element (FE) model of roofing sheet structure consists of corrugated roof hollow sheet, two C-sectional purlins, and six fasteners. Two uniformly distributed loads will be shown in two areas. The FE model is shown in Figure 11.
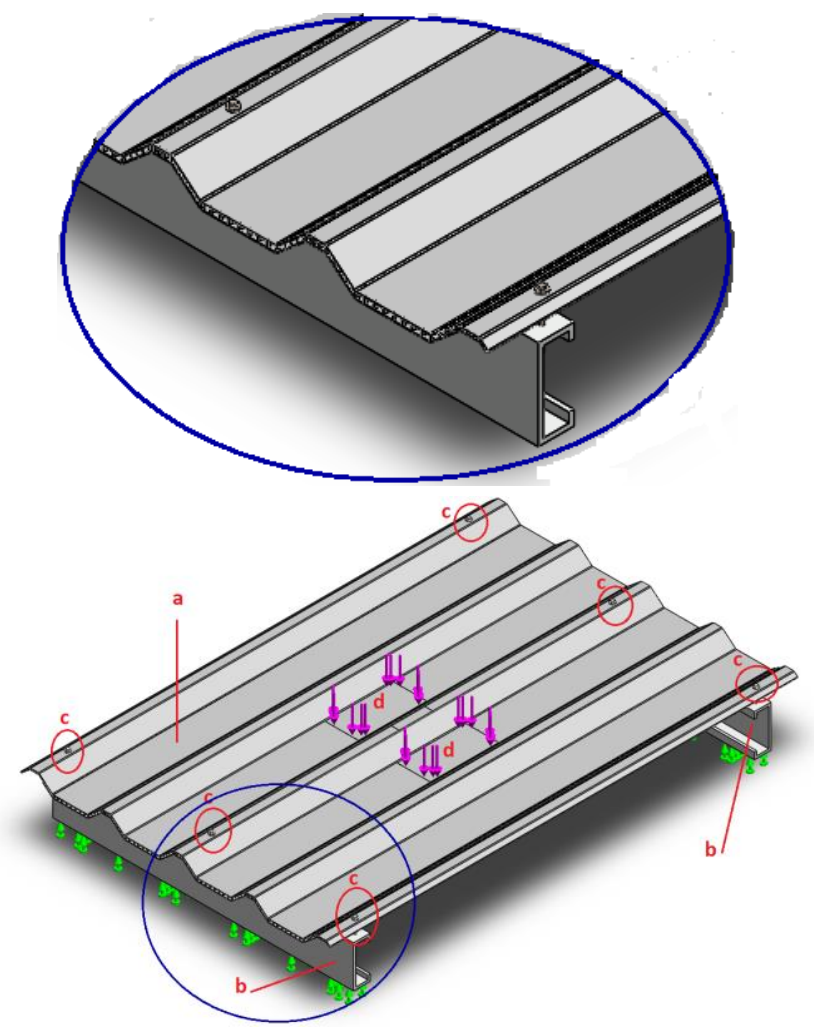

Fig. 11. Roofing sheet structure: (a) roofing sheet, (b) purlins, (c) fasteners, (d) uniform load areas
Table 3. Messing of roofing sheet

\begin{tabular}{|c|c|}
\hline Study name & Static \\
\hline Mesh type & Solid Mesh \\
\hline Mesher Used & Curvature based mesh \\
\hline Jacobian points & 4 points \\
\hline Max Element Size & $10.2414 \mathrm{~mm}$ \\
\hline Min Element Size & $2.04827 \mathrm{~mm}$ \\
\hline Mesh quality & High \\
\hline Total nodes & 2078922 \\
\hline Total elements & 1121071 \\
\hline $\begin{array}{c}\text { Time to complete } \\
\text { mesh(hh:mm:ss) }\end{array}$ & $0: 08: 50$ \\
\hline
\end{tabular}

The selected element is a triangle element. Automatic meshing is the initial step for estimating. It is done using the menus available in the software. Furthermore refinement is done using global mesh with the appropriate size and if necessary the part that need detail by using local mesh. In this case a small dimension of the rib is modelled according to the actual size. Small meshing is done on the area. The results are shown in Table 3 and Figure 12.

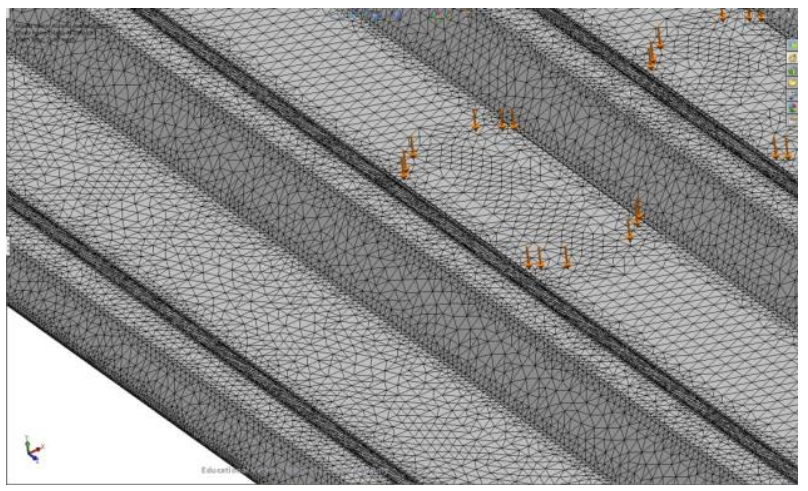

Fig. 12. Messing of roofing sheet

Roof material that will be used in the first simulation is rigid PVC from material library of the software with modulus of elasticity of $2410 \mathrm{MPa}$ [9]. The fasteners are selected of stainless steel material and the purlins are Eglass GFRP material. The deflection of dial 1 and dial 2 generated by various values of static load and its comparison to the experimental results is shown in Table 4, Figure 13 and Figure 14. It shows that the average difference of both reaches $23 \%$ for dial 1 and $15 \%$ for dial 2. The difference is large, so the FE model is said not similar to the actual structure.

Table 4. Deflection of experimental and FE (for rigid PVC)

\begin{tabular}{|c|c|c|c|c|c|c|}
\hline \multirow{3}{*}{$\begin{array}{c}\text { Load } \\
(\mathrm{kg})\end{array}$} & \multicolumn{2}{|c|}{$\begin{array}{c}\text { Deflection }(\mathrm{mm}) \\
\text { (experimental) }\end{array}$} & \multicolumn{2}{|c|}{$\begin{array}{l}\text { Deflection (mm) } \\
\text { (FE) }\end{array}$} & \multirow{2}{*}{\multicolumn{2}{|c|}{$\begin{array}{l}\text { percentage of } \\
\text { difference }(\%)\end{array}$}} \\
\hline & \multirow{2}{*}{\begin{tabular}{|c|} 
Dial 1 \\
3.45 \\
\end{tabular}} & \multirow{2}{*}{$\begin{array}{c}\text { Dial } 2 \\
4.16 \\
\end{array}$} & \multirow{2}{*}{$\begin{array}{c}\text { Dial 1 } \\
2.73\end{array}$} & \multirow{2}{*}{$\begin{array}{c}\text { Dial } 2 \\
2.76 \\
\end{array}$} & & \\
\hline & & & & & -20.96 & -33.75 \\
\hline 22.3 & 6.87 & 6.9 & 5.34 & 5.39 & -22.34 & -21.87 \\
\hline 33.5 & 10.2 & 9.03 & 8.01 & 8.10 & -21.43 & -10.31 \\
\hline 44.7 & 13.02 & 12.74 & 10.69 & 10.81 & -17.87 & -15.17 \\
\hline 55.7 & 16.76 & 15.04 & 13.33 & 13.47 & -20.50 & -10.47 \\
\hline 67.1 & 20.89 & 17.6 & 16.05 & 16.22 & -23.16 & -7.82 \\
\hline 77.7 & 24.87 & 21.69 & 18.59 & 18.79 & -25.26 & -13.39 \\
\hline 88.7 & 29.4 & 24.74 & 21.22 & 21.45 & -27.82 & -13.32 \\
\hline 100.3 & 33.64 & 28.12 & 24.00 & 24.25 & -28.67 & -13.77 \\
\hline & & & & Average & -23.11 & -15.54 \\
\hline
\end{tabular}




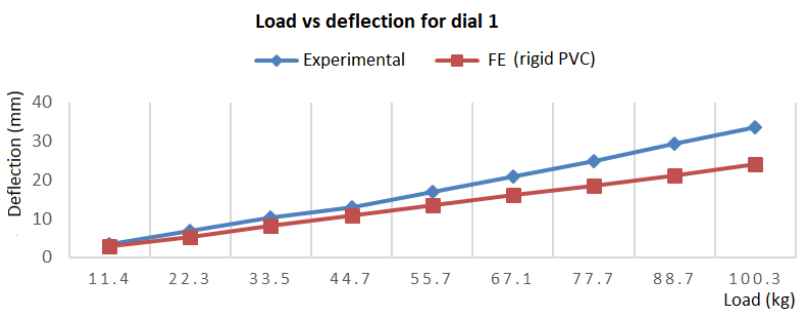

Fig. 13. Load vs deflection of experimental and FE for dial 1

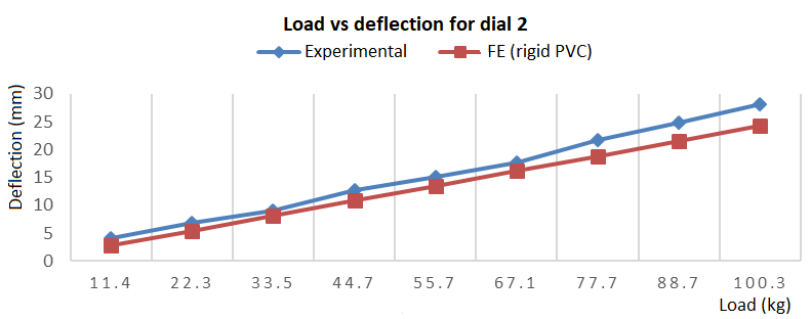

Fig. 14. Load vs deflection of experimental and FE for dial 2

In the next simulation, the mechanical properties of the rigid PVC material is changed. The modulus of elasticity of UPVC material is taken $2000 \mathrm{MPa}$ and the yield strength is $20 \mathrm{MPa}$ [11]. The deflection of dial 1 and dial 2 generated by various values of static load and its comparison to the experimental results is shown in Table 5, Figure 15 and Figure 16. It shows that the average difference of both reaches $10.96 \%$ for dial 1 and $2.21 \%$ for dial 2 . The difference is relatively small especially for dial 2 . The difference in deflection between experimental and FE for dial 1, although it is not large, $10.96 \%$ is caused by non-uniformity bricks load in experimental cases. On the other hand, the material properties and static load of the FE model must be uniformed. However, this FE model can be stated to be valid because the FE deflection is close to the experimental deflection.

Table 5. Deflection of experimental and FE (for rigid PVC)

\begin{tabular}{|c|c|c|c|c|c|c|}
\hline \multirow{2}{*}{$\begin{array}{c}\text { Load } \\
(\mathrm{kg})\end{array}$} & \multicolumn{2}{|c|}{$\begin{array}{c}\text { Deflection }(\mathrm{mm}) \\
\text { (experimental) }\end{array}$} & \multicolumn{2}{|c|}{$\begin{array}{l}\text { Deflection (mm) } \\
\text { (FE) }\end{array}$} & \multirow{2}{*}{\multicolumn{2}{|c|}{$\begin{array}{l}\text { percentage of } \\
\text { difference (\%) }\end{array}$}} \\
\hline & Dial 1 & Dial 2 & Dial 1 & Dial 2 & & \\
\hline 11.4 & 3.45 & 4.16 & 3.16 & 3.19 & -8.46 & -23.32 \\
\hline 22.3 & 6.87 & 6.90 & 6.18 & 6.24 & -10.07 & -9.55 \\
\hline 33.5 & 10.20 & 9.03 & 9.28 & 9.38 & -9.01 & 3.82 \\
\hline 44.7 & 13.02 & 12.74 & 12.38 & 12.51 & -4.89 & -1.81 \\
\hline 55.7 & 16.76 & 15.04 & 15.43 & 15.59 & -7.92 & 3.64 \\
\hline 67.1 & 20.89 & 17.60 & 18.59 & 18.78 & -11.01 & 6.69 \\
\hline 77.7 & 24.87 & 21.69 & 21.53 & 21.74 & -13.44 & 0.25 \\
\hline 88.7 & 29.40 & 24.74 & 24.58 & 24.88 & -16.41 & 0.57 \\
\hline 100.3 & 33.64 & 28.12 & 27.79 & 28.07 & -17.39 & $\begin{array}{l}-0.18 \\
\end{array}$ \\
\hline & & & & Average & -10.96 & -2.21 \\
\hline
\end{tabular}

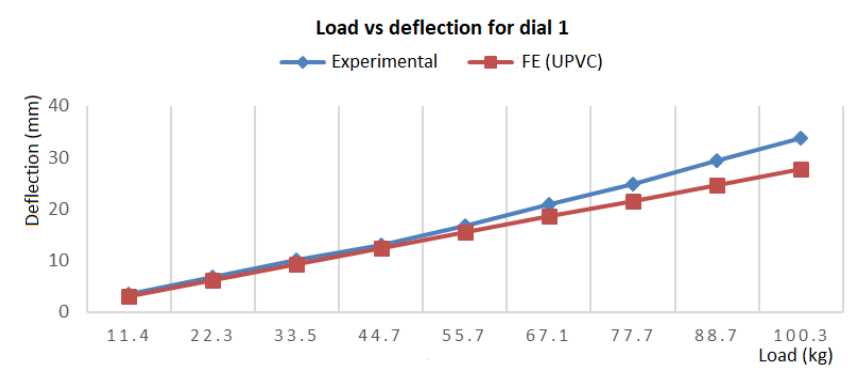

Fig. 15. Load vs deflection of experimental and FE for dial 1

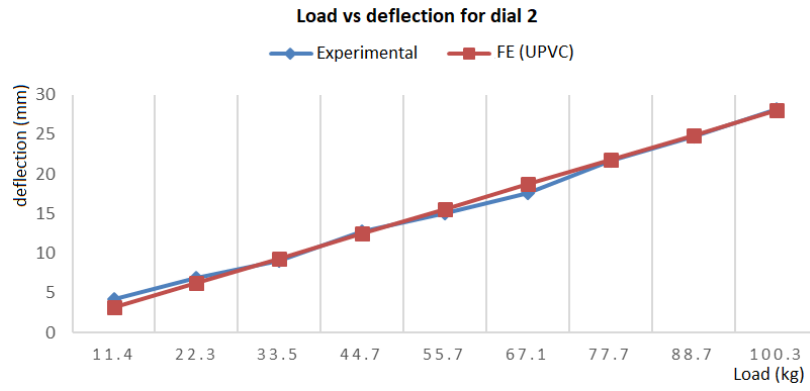

Fig. 16. Load vs deflection of experimental and FE for dial 2

\subsection{Simulation of the roofing sheet structure}

The valid FE model of the roofing structure can be used to simulate various static loads. The mechanical properties of the UPVC material used are $20 \mathrm{MPa}$ for yield strength and $2000 \mathrm{MPa}$ for modulus of elasticity.

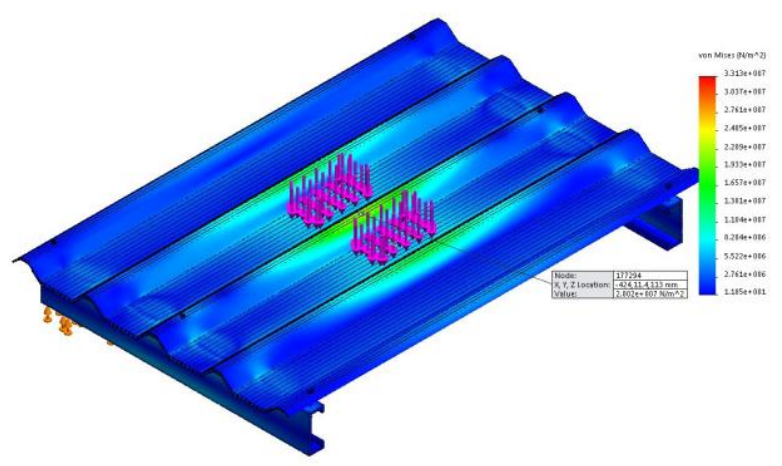

Fig. 17. Stress distribution

Table 6. Simulation of roofing sheet structure

\begin{tabular}{|c|c|c|}
\hline $\begin{array}{c}\text { Load } \\
(\mathrm{kg})\end{array}$ & $\begin{array}{c}\text { Stress at the center of cross } \\
\text { section of the roof }\left(\mathrm{N} / \mathrm{m}^{2}\right)\end{array}$ & Note \\
\hline 88.7 & $1.335 \times 10^{7}$ & \\
\hline 100.3 & $1.510 \times 10^{7}$ & \\
\hline 111.0 & $1.671 \times 10^{7}$ & \\
\hline 122.0 & $1.836 \times 10^{7}$ & \\
\hline 133.0 & $2.002 \times 10^{7}=20.02 \mathrm{MPa}$ & Yield stress \\
\hline
\end{tabular}

The first simulation is determination the uniform load until the roof structure failed. The roof structure is fail at a certain load if the greatest Von Mises stress has reached the yield stress. The simulation shows that the yield stress is achieved at $133 \mathrm{~kg}$ load as shown in Figure 17 and Table 6 . This $133 \mathrm{~kg}$ load is equivalent to a mass of two roof applicators. Thus it can be concluded that the roof structure is able to withstand two roof applicators.

The second simulation is determination the pressure from the below of the roof structure that causes the roof fail as shown in Figure 18 and Table 7. The roof structure is fail at a certain pressure if the greatest Von Mises stress has reached the yield stress. 


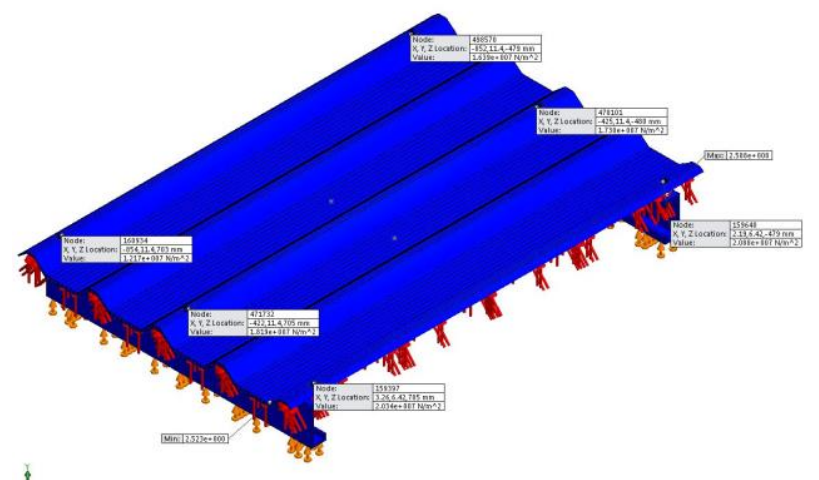

Fig. 18. Pressure simulation

Table 7. Pressure and Von Mises stress around the fasteners

\begin{tabular}{|c|c|c|}
\hline $\begin{array}{c}\text { Pressure } \\
\left(\mathrm{N} / \mathrm{m}^{2}\right)\end{array}$ & $\begin{array}{c}\text { Stress around the fasteners } \\
\left(\mathrm{N} / \mathrm{m}^{2}\right)\end{array}$ & Note \\
\hline \multirow{4}{*}{100} & $0.339 \times 10^{7}$ & \\
\hline & $0.112 \times 10^{7}$ & \\
\hline & $0.32 \times 10^{7}$ & \\
\hline & $0.409 \times 10^{7}$ & \\
\hline & $0.264 \times 10^{7}$ & \\
\hline & $0.309 \times 10^{7}$ & \\
\hline \multirow{4}{*}{300} & $1.082 \times 10^{7}$ & \\
\hline & $0.880 \times 10^{7}$ & \\
\hline & $1.181 \times 10^{7}$ & \\
\hline & $1.062 \times 10^{7}$ & \\
\hline & $0.857 \times 10^{7}$ & \\
\hline & $1.16 \times 10^{7}$ & \\
\hline \multirow{4}{*}{600} & $1.217 \times 10^{7}$ & \\
\hline & $1.819 \times 10^{7}$ & \\
\hline & $2.034 \times 10^{7}$ & \\
\hline & $2.088 \times 10^{7}=20.34 \mathrm{MPa}$ & Yield stress \\
\hline & $1.730 \times 10^{7}$ & \\
\hline & $1.639 \times 10^{7}$ & \\
\hline
\end{tabular}

Table 7 shows that the pressure of $600 \mathrm{~N} / \mathrm{m}^{2}$ or $12.531 \mathrm{lb} / \mathrm{ft}^{2}$ causes the roof fail. According to Noris et.al. [12], the pressure is equivalent to the wind rate of:

$$
p=0,0033 v^{2}
$$

Where $: p$ is pressure $\left(\mathrm{lbf} / \mathrm{ft}^{2}\right)$

$\mathrm{v}$ is wind speed (miles/ hour, $\mathrm{mph}$ )

The wind speed is :

$$
v=\sqrt{\frac{1{ }_{z} 531}{0,0033}}=61,622 \mathrm{mph}=99 \mathrm{~km} / \mathrm{h}
$$

It can be concluded that the roof structure is able to withstand of wind speed or wind lift force equivalent to $99 \mathrm{~km} / \mathrm{h}$.

\section{Conclusions}

The conclusions are,

1) The new design of a roofing sheet from UPVC polymer material is a hollow corrugated roofing sheet with five crests and four valleys. The effective width is $860 \mathrm{~mm}, 10 \mathrm{~mm}$ cavity thick, and $45 \mathrm{~mm}$ peak height. The roof cross sectional thickness is $1 \mathrm{~mm}$ except $0.8 \mathrm{~mm}$ for the top sheet.

2) The valid FE model of the roofing sheet structure gives the information that the structure is capable of withstanding the static load/ mass of $133 \mathrm{~kg}$ equivalent of two applicators and capable of withstanding the wind lift force equivalent to 99 $\mathrm{km} / \mathrm{h}$.

Special thanks to Mr. Alex Hendro, President Director of PT Intec Persada-Indonesia, for allowing the author to utilize company facilities to conduct the research.

\section{References}

1. D. Setyanto. Procedia Engineering 171. 17 (2017)

2. M. Zainudin. K. Diharjo. M. Kaavessina. D. Setyanto. AIP Conf. Proc. 1931. 030063 (2018)

3. P.S. Rao. M.M. Husain. Indian Journal of Engineering \& Materials Sciences 23. 288-296 (2016)

4. D. Setyanto. AIP Conf. Proc. 1717. 040007 (2016)

5. D. Setyanto. Procedia Engineering 95. 498-503 (2014)

6. E. Yousif. A. Hasan. Journal of Taibah University for Science 9. 421-448 (2015)

7. L.E.P. Real. A.M. Ferraria. A.M.B. do Rego. Polymer Testing 27. 743-751 (2008)

8. G. Pahl. W. Beitz. J. Feldhusen. K.H. Grote Engineering Design - A Systematic Approach . $3^{\text {rd }}$ ed. (Springer, 2007)

9. Dassault Systemes Solidworks Corp. 1995. Solidworks 2015 Education Version Academic Year 2015-2016 SP 5.0. (2015)

10. BlueScope Lysaght Limited. Roofing \& walling user manual guide 2008-2009 (2008)

11. Griffey. J.. Types of Plastics (Chapter 3). Library Technology Reports. 50(5).pp.13-15 (2014)

12. C.H. Norris, J.B. Wilbur, S. Utku, Elementary structural analysis, $3^{\text {rd }}$ ed., (McGraw-Hill Book Co., Singapore, 1977) 